\title{
DESKRIPSI TEKNIS PENGENDALI TINGGI MUKA CAIRAN INDUSTRI MENGGUNAKAN METODE FLOATLESS OMRON 61F
}

\author{
Dista Yoel Tadeus, Iman Setiono \\ Program Studi D iploma III Teknik Elektro \\ Sekolah Vokasi, Universitas Diponegoro \\ Jl. Prof. Soedarto, SH, Kampus Undip Tembalang, Semarang, Indonesia 50275
}

\begin{abstract}
Dista Yoel Tadeus, Iman Setiono, in this paper explain that device for controlling liquid/water level using the floatless method uses the character of liquid conductivity as an electric current carrying medium. Excitation voltage is generated by the controller and passed to the electrode through an insulated conductor cable. The electrode is submerged in a tank or liquid storage vessel and directly becomes the lower limit and upper limit of the liquid level. Omron $61 \mathrm{~F}$ is one of the industry-standard floatless control devices that is simple, compact and relatively inexpensive and easily available on the market. Some applications for controlling liquid levels such as water supply and drainage can be done easily and simple wiring. Omron $61 F$ provides a variety of controller types that are tailored to the application conditions and the type of liquid used, ranging from purified clean water, dirty water, salt water, to several types of acidic liquids. Wiring method for filling and emptying the liquid tank application can be easily achieved with Omron $61 F$ controller as described on this paper. Commonly found problem, the presence of dirt or material attached to the electrode connection can be easily mitigated by performing regularly electrode cleaning.
\end{abstract}

Keywords: Liquid / Water Level Controller; floatless controller; Omron 61F;

\section{PENDAHULUAN}

Tinggi muka cairan atau yang lebih khusus disebut dengan water level (untuk air) adalah sebuah variabel ukur yang sangat mudah sekali dijumpai dalam kehidupan sehari-hari. Mulai dari yang sederhana seperti pada tangki air toilet seperti yang ditunjukkan oleh gambar 1 dan tangki air bersih di rumah seperti yang ditunjukkan oleh gambar 2 hingga yang kompleks pada mesin dan proses produksi di industri. Sesuai dengan kebutuhan aplikasinya, ketinggian muka air dapat bersifat hanya sebagai variabel monitoring saja atau sebagai variabel yang dikendalikan. Perangkat yang umum digunakan dalam upaya pengendalian tinggi muka air biasa disebut Water Level Controller (WLC). Di dalam alat tersebut umumnya terdiri dari satu set sensor, pengendali dan aktuator.

Desain WLC yang mampu mendeteksi dan mengendalikan tinggi air pada tangki air khusus atau sistem penyimpanan air yang mirip telah dibuat oleh B. Getu dkk dengan memanfaatkan rangkaian logika sekuensial flip-flop sebagai pengendalinnya [1]. WLC digunakan pada aplikasi sistem irigasi pertanian otomatis menggunakan mikrokontroler berbasis Intel 8051 [2]. WLC juga digunakan pada sistem operasi perbedaan tinggi air kanal utama di Central Arizona Irrigation and Drainage District (CAIDD), Eloy, AZ [3]. Peralatan generator uap pada instalasi reaktor nuklir menggunakan WLC yang terintegrasi dengan dua jenis kontroler utama yaitu feedback controller dan feedforward controller demi mencapai performa yang merata di semua daya [4].

Di sektor industri dan aplikasi yang sifatnya general purpose terdapat pilihan WLC yang siap pakai dan beragam jenis, umumnya berdesain kompak, mudah dipasang, dan memiliki kehandalan tinggi. Salah satu jenis WLC tersebut yang mudah dijumpai di pasaran dan digunakan luas di banyak aplikasi adalah keluarga 61F-G keluaran merek Omron. Artikel ini akan memberikan uraian berupa deskripsi teknis mengenai WLC tersebut beserta dengan beberapa contoh aplikasinya.

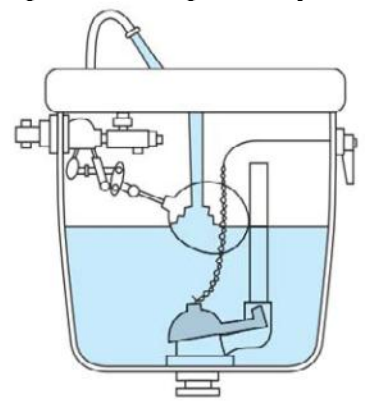

Gambar 1. WLC tipe float dengan pelampung berlengan mekanik pada tangki toilet duduk
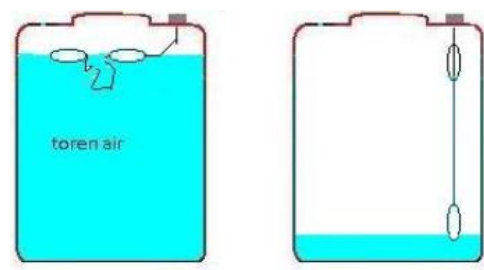

Gambar 2. WLC tipe float dengan pelampung bertali pada tangki air bersih 


\section{TINJAUAN PUSTAKA \\ WLC Omron 61F}

WLC Omron 61F merupakan salah satu jenis WLC general purpose dari Omron yang mudah untuk dipasang dalam panel dan mudah maintenance. WLC ini tidak menggunakan pelampung (floatless) tapi menggunakan elektroda khusus dengan sambungan kabel yang dialiri arus listrik, aktuatornya berupa relay elektromekanik yang jumlahnya dapat dipilih sesuai dengan line-up dari keluarga 61F-G seperti yang ditunjukkan oleh gambar 3 [5].

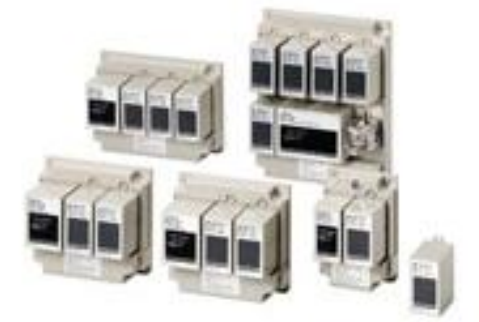

Gambar 3. Line-up keluarga WLC 61F

WLC dengan tipe floatless memiliki banyak keunggulan dibanding dengan tipe float, seperti: tidak ada gangguan eksternal berupa gerakan mekanik pada pelampung, tidak ada gangguan karena tali pelampung yang kusut, tidak ada batasan pada panjang lengan mekanik pelampung, tidak ada gangguan karat pada mekanisme pelampung. Selain itu jika dibandingkan dengan WLC yang berbasis kapasitansi dan berbasis ultrasonic (rentan terhadap gangguan gelombang permukaan), 61F memungkinkan pendeteksian tinggi air yang lebih stabil dan konsisten pada harga yang relatif rendah. Tabel 1 menunjukkan perbandingan line-up WLC Omron 61F sesuai dengan aplikasi, jenis cairan atau kondisi operasi yang diperuntukkan. Salah satu parameter cairan yang perlu diperhatikan adalah nilai resistivitas spesifik cairan, apabila nilainya tinggi disarankan untuk menggunakan model WLC yang berjenis sensitivitas tinggi (tipe $\mathrm{H}$ ). Tabel 2 menunjukkan nilai resistivitas air di beberapa instalasi secara umum.

\section{METODE PENELITIAN \\ Prinsip Operasi WLC Omron 61F}

WLC bekerja dengan prinsip penghantaran arus listrik melalui media cairan yang konduktif. Pada tingkat yang paling sederhana dapat menggunakan dua buah elektroda seperti ditunjukkan oleh gambar 4. Ketika elektroda E1 tidak kontak dengan cairan yang konduktif, sirkuit menjadi terputus, dan tidak ada arus mengalir di antara elektroda E1 dan E3. Akibatnya, relay X tidak beroperasi. Relai kontak Normally Closed (NC) X. (biasanya tertutup, b pada gambar 4) tetap tertutup. Namun, saat cairan disuplai ke tangki, sehingga cairan kontak dengan E1, sirkuit menjadi tertutup sesuai gambar 5. Relay X beroperasi, dan perangkat listrik terhubung ke kontak Normally Opened (NO) (biasanya terbuka, pada gambar 5).

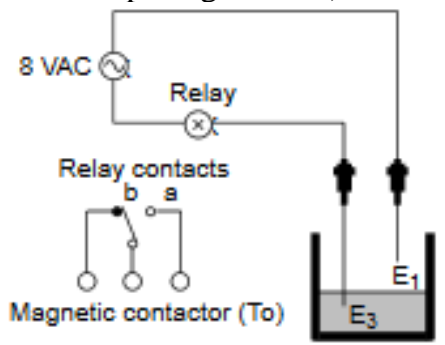

Gambar 4. E1 tidak terhubung ke E3

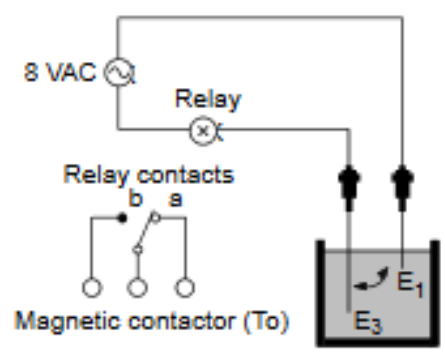

Gambar 5. E1 terhubung ke E3 melalui cairan

Sebuah pompa biasanya dihubungkan ke kontaktor, yang juga terhubung ke output kontak WLC dan akan mengoperasikan pompa secara otomatis untuk mengontrol level cairan dalam tangki. Namun, dalam praktiknya, dengan hanya dua elektroda, riak pada permukaan muka cairan akan menyebabkan WLC terlalu sering hidup dan mati, sehingga memperpendek usia pakai pompa dan peralatan lainnya. Masalah ini dapat diselesaikan dengan menempatkan elektroda lain untuk membentuk sirkuit latch (penahan). Elektroda tambahan, E2, terhubung secara paralel dengan E1, seperti yang ditunjukkan gambar 6 .

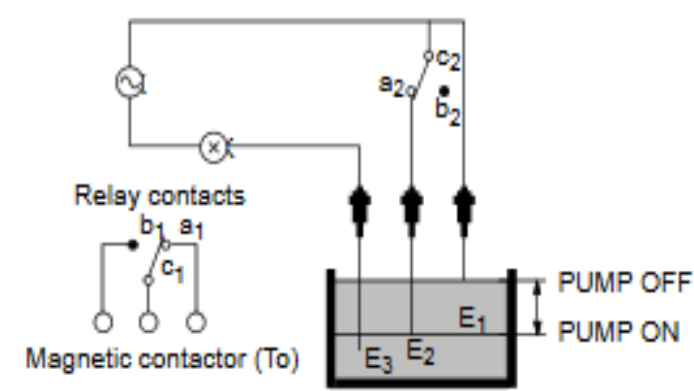

Gambar 6. Elektroda tambahan E2

Seperti yang ditunjukkan pada gambar 6, saat relai X sirkuit penahan diaktifkan, kontak $\mathrm{a}_{2} \mathrm{NO}$ tertutup. Arus listrik mengalir melalui cairan dan elektroda E2 dan E3, bahkan ketika tinggi cairan turun di bawah E1, kondisi tersebut terjadi selama kontak $a_{2}$ tertutup. Ketika tinggi cairan berada di bawah E2, sirkuit penahan menjadi terbuka dan arus listrik terputus dan menonaktifkan relai penahan $\mathrm{X}$, sehingga kontaknya kembali ke posisi $\mathrm{NC}$ yaitu $\mathrm{b}_{2}$ [6]. 


\section{Diagram Sirkuit Internal}

Gambar 7 menunjukkan diagram sirkuit internal dari WLC Omron tipe 61F-G. Tampak di dalamnya terdapat rangkaian catu daya yang dapat disuplai oleh tegangan 110 atau 220 VAC, selain itu juga terdapat relay unit $61 \mathrm{~F}-11$ yang memiliki kontak interlock U. Dari gambar 7 diketahui bahwa tegangan eksitasi elektroda adalah $8 \mathrm{VAC}$.

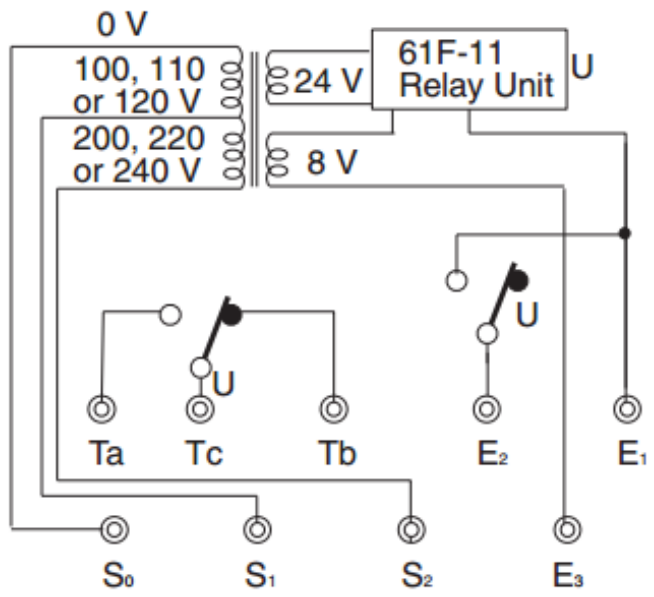

Gambar 7. Diagram sirkuit internal 61F-G

\section{Elektroda WLC}

Pemilihan elektroda WLC disesuaikan dengan aplikasi atau material cairan yang digunakan dan dapat mengacu kepada tabel 2. Gambar 8 menunjukkan bentuk elektroda secara umum.

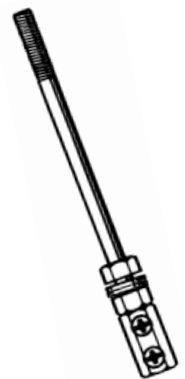

Gambar 8. Elektroda WLC

\section{HASIL DAN PEMBAHASAN \\ Aplikasi WLC Omron 61F-G}

Beberapa contoh aplikasi WLC secara umum disajikan dalam uraian berikut:

- Pengendalian pengisian tangki air otomatis

Aktivitas yang dilakukan pada aplikasi ini adalah memindahkan air dari sebuah penampungan tertentu menggunakan pompa ke tangki air yang dikontrol proses pengisiannya. Kerja pompa diatur sesuai dengan kondisi tinggi air di dalam tangki. Apabila tinggi air minimal (kosong) maka pompa aktif dan bila tinggi air maksimal (penuh) maka pompa nonaktif. Diagram pengkabelan beserta ilustrasinya ditunjukkan oleh gambar 9. Prinsip kerjanya adalah sebagai berikut, jika hanya E3 yang terendam air (kosong) kontak $\mathrm{Tb}$ dan Tc terhubung dan pompa akan hidup lalu air akan naik terus sampai merendam E2, sampai di sini pompa tetap hidup sehingga air akan naik terus sampai merendam E1. Ketika semua elektroda terendam air (penuh) maka relai penahan bekerja. Arus listrik saat ini mengalir dari elektroda E3 melalui media air ke elektroda E1 dan E2. Pada saat yang sama kontak Tb dan Tc menjadi terputus sehingga memutus sinyal kendali pompa dan pompa akan mati. Ketika level air kemudian menurun sehingga hanya E2 dan E3 yang terendam air, pompa tetap mati karena arus listrik masih mengalir dari E3 ke E2 melalui media air. Jika air terus menurun sampai hanya E3 yang terendam air (kosong) relai penahan menjadi nonaktif dan arus listrik tidak dapat mengalir dari E3 menuju elektroda lain yang kemudian menyebabkan kontak $\mathrm{Tb}$ dan $\mathrm{Tc}$ menjadi terhubung sehingga sinyal kendali kembali terhubung untuk menghidupkan pompa.

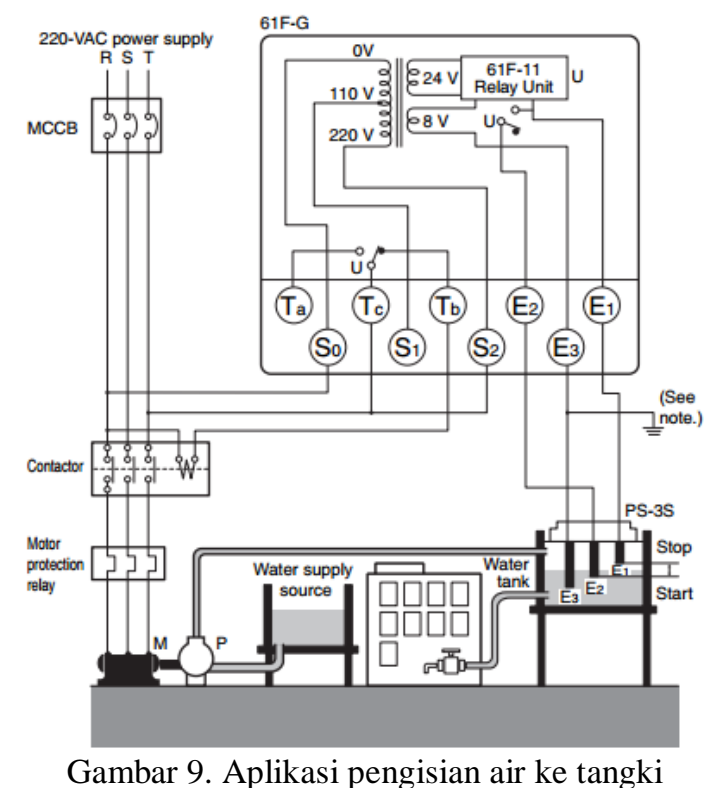

- Pengendalian pengosongan tangki air otomatis Aktivitas yang dilakukan pada aplikasi ini adalah memindahkan air dari tangki air ke sebuah penampungan tertentu menggunakan pompa yang dikontrol proses pengosongannya. Kerja pompa diatur sesuai dengan kondisi tinggi air di dalam tangki. Apabila tinggi air maksimal (penuh) maka pompa aktif dan bila tinggi air minimal (kosong) maka pompa nonaktif. Diagram pengkabelan beserta ilustrasinya ditunjukkan oleh gambar 10. Prinsip kerjanya adalah sebagai berikut, jika E1, E2, dan E3 terendam air (penuh) kontak Ta dan Tc terhubung dan pompa akan hidup dan relai penahan aktif lalu air akan terkuras sampai E2 tidak terendam, sampai di sini pompa tetap hidup sehingga air akan terkuras terus sampai hanya merendam E1. Ketika hanya E1 yang terendam air (kosong) maka relai penahan nonaktif. Arus listrik tidak mengalir melalui elektroda E2 atau E1. Pada saat yang sama kontak Ta dan Tc menjadi terputus sehingga memutus 
sinyal kendali pompa dan pompa akan mati. Pompa akan hidup kembali apabila tinggi air di dalam tangki merendam E1, E2, dan E3.

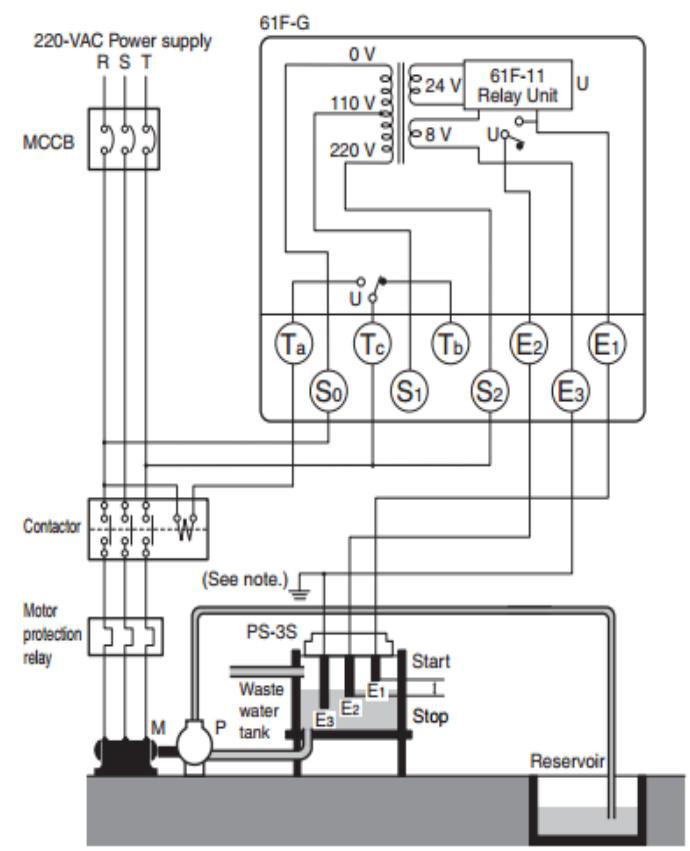

Gambar 10. Aplikasi pengosongan air tangki ke penampungan

Untuk aplikasi yang lebih kompleks misalnya dibutuhkan kemampuan untuk mengindikasikan level air di dalam tangki serta kemampuan mengaktifkan alarm, dapat menggunakan jenis WLC 61F yang memiliki lebih dari satu relai seperti yang ditunjukkan pada gambar 11 dalam aplikasi pengendalian pengisian air ke tangki sekaligus monitoring level air tangki dan alarm. WLC yang digunakan berjenis 61F-I.

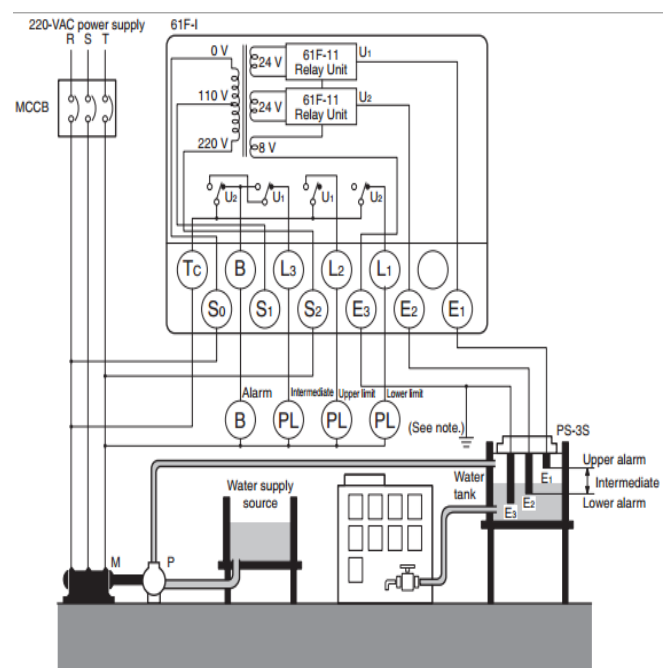

Gambar 11. Aplikasi pengisian air dengan fitur alarm dan indikasi tinggi air

Apabila terdapat aplikasi yang menggunakan sumber listrik 3 fasa dengan netral maka cara pengkabelannya dapat merujuk ke gambar 12 .

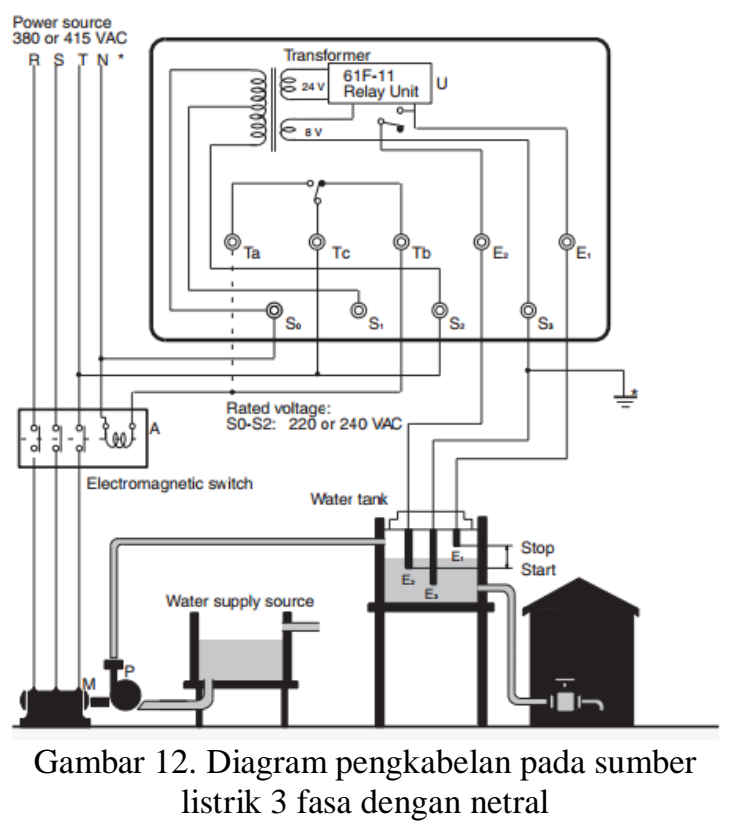

\section{Masalah pada WLC}

Masalah yang umum dijumpai pada WLC adalah adanya kotoran atau material yang menempel di sambungan elektroda dan kabel penghubung sehingga mengganggu hantaran arus listrik ke elektroda. Jika masalah tersebut timbul pada WLC di sistem pengurasan air maka akan terjadi kesalahan deteksi level air. Contohnya bila level air aktual masih di kisaran setengah dari tinggi maksimal (E3 dan E2 masih terendam air) dan arus listrik dari elektroda E3 menuju E2 terputus dikarenakan kotoran, maka WLC akan menganggap level air sudah sampai di titik terendah (kondisi kosong) sehingga pompa akan berhenti.

Masalah tersebut dapat diatasi dengan cara sebagai berikut:

- Mematikan sistem secara keseluruhan

- Melepas hubungan elektroda dan kabel penghubung

- Membersihkan logam elektroda dan konduktor kabel penghubung

- Memasang kembali elektroda dan kabel penghubung

- Menghidupkan sistem kembali

\section{KESIMPULAN}

WLC Omron 61F menyediakan solusi pada kebutuhan pengendalian tinggi muka cairan dengan berbagai jenis dan tipe yang disesuaikan dengan aplikasi dan jenis cairan yang digunakan seperti tipe general purpose 61F-G yang dapat diaplikasikan pada instalasi air bersih, air kotor, dan air yang dimurnikan secara umum. Tipe $61 \mathrm{~F}$ dengan sufiks $\mathrm{L}$ dan $\mathrm{H}$ masing-masing dikhususkan bagi instalasi cairan yang tempatnya jauh dan memiliki karakter resistivitas yang tinggi. Beberapa aplikasi seperti pengisian maupun pengosongan cairan di dalam tangki dapat diterapkan dengan mudah melalui pengkabelan yang mudah dan sederhana. Masalah 
yang umum dijumpai adalah elektroda yang seiring waktu dapat menjadi kotor dan dapat mudah diatasi dengan cara membersihkan elektroda secara berkala.

\section{DAFTAR PUSTAKA}

1. Getu, B. N., \& Attia, H. A. (2017). Automatic water level sensor and controller system. In International Conference on Electronic Devices, Systems, and Applications. https://doi.org/10.1109/ICEDSA.2016.7818550

2. Ebere, E. V., \& Francisca, O. O. (2013). Microcontroller based Automatic Water level Control System. International Journal of Innovative Research in Computer and Communication Engineering.

3. Clemmens, A. J. (2012). Water-Level Difference Controller for Main Canals. Journal of Irrigation and Drainage Engineering. https://doi.org/10.1061/(ASCE)IR.19434774.0000367

4. Tan, W. (2011). Water level control for a nuclear steam generator. In Nuclear Engineering and Design. https://doi.org/10.1016/j.nucengdes.2010.12.010

5. Omron. Floatless Level Controller 61F.

6. Omron. Floatless Level Switch 61F-G. 